\title{
DIDAKTIČKO OBLIKOVANJE ZADATAKA ZA SAMOEVALUACIJU U UDŽBENICIMA ENGLESKOG KAO STRANOG JEZIKA
}

SLOBODANKA GLIGORIĆ ${ }^{1}$

Filološka gimnazija, Beograd

Srbija

\begin{abstract}
Autonomija učenika je termin koji se sve češće koristi u literaturi vezanoj za usvajanje stranog jezika i predstavlja sposobnost učenika da preuzme odgovornost za sopstveno učenje. Ovaj rad ima za cilj da predstavi samoevaluaciju kao ključnu komponentu u ostvarivanju autonomije učenika pri usvajanju stranog jezika u okviru formalnog školskog sistema, kao i da istakne značaj udžbenika u razvoju sposobnosti za samoevaluaciju. Poseban naglasak stavlja se na principe didaktičkog oblikovanja zadataka za samoevaluaciju, kao i na njihov uticaj na nastavnu praksu.
\end{abstract}

KLJUČNE REČI: samoevaluacija, samoregulisano učenje, teorija socijalnog učenja.

\section{UVOD}

Od osamdesetih godina prošlog veka, razvojem pristupa nastavi koji u centar interesovanja stavlja učenika, sve više se propagira ideja autonomije u učenju stranog jezika. Čak se i Savet Evrope pri razvijanju Evropskog jezičkog portfolija (EJP) bazirao na teoriji o autonomiji učenika koja promoviše takozvano "doživotno učenje". Načini posmatranja autonomije menjali su se vremenom, od samostalnog učenja van školskih institucija koje je bilo fokus ranijih teorija, ka autonomiji učenika u učionici. Sva ova stanovišta polaze od zajedničke ideje o stvaranju samostalnog učenika koji će biti u stanju da preuzme odgovornost za sopstveno učenje (Holec 1981: 3) bilo u učionici ili van nje i da zatim stečene kognitivne strategije prenese i na druge sfere života. Kao osnovni elementi autonomnog učenja uzimaju se reflektivni pristup procesu učenja (Vrhovac/Mihaljević Đigunović 2010: 237) koji podrazumeva razvijanje sposobnosti učenika da razmišljaju o onome što se događa kada uče jezik i samoevaluacija kao

1 Kontakt podaci (Email): slobodankagligoric@gmail.com 
proces vrednovanja sopstvenog rada i dostignuća. Ova dva procesa su u međuzavisnom odnosu, što se da zaključiti iz navoda Klenovskog koji definiše samoevaluaciju kao „procenu ,vrednosti' sopstvenog učinka i identifikaciju svojih jakih i slabih strana u cilju poboljšanja rezultata učenja" (Klenowski 1995: 146). Drugim rečima, razvijanjem kritičke samo-refleksije učenici bi trebalo da razviju svest o procesu učenja i tako budu u stanju da na isti pozitivno utiču i određuju mu tok. Svest o tome koliko smo uspešni u usvajanju znanja, predstavlja prvi korak ka samoregulaciji i autonomiji neophodnim za doživotno učenje.

\section{SAMOEVALUACIJA KAO VID ODRŽIVE EVALUACIJE}

Procena uspeha ishoda učenja neodvojivi je deo procesa usvajanja znanja, $\mathrm{i}$ tradicionalno se svrstava u dve kategorije: sumativni i formativni tip. Na ova dva vida evaluacije, od skora se dodaje još jedan, a to je održiva evaluacija (sustainable assessment) čiji je direktan cilj promocija doživotnog učenja. Prvobitno definisana kao „evaluacija koja zadovoljava potrebe sadašnjice i priprema učenika da u budućnosti ispuni sopstvene potrebe u učenju" (Boud 2000: 152), danas se posmatra kao onaj vid evaluacije koji „zadovoljava buduće potrebe, a ne dovodi u pitanjesposobnostučenika da ispune sadašnje potrebe u učenju" (Cooker 2015: 92). Drugim rečima, održiva evaluacija ima za cilj da omogući i podrži doživotno učenje tako što će uključiti učenike u proces evaluacije, pomoći im da razviju sposobnost procene i „osećaj sopstva“" (ibid.) i negovati reflektivni pristup i samoregulaciju (Boud 2000). Ukoliko prihvatimo tvrdnju da sa tačke gledišta učenika evaluacija definiše kurikulum (Rowntree 1977: 1) jer promoviše bilo kulturu učenja bilo kulturu ocenjivanja (Hamp-Lyons 2007: 488), pretpostavka je da kroz angažovanje na ovom polju možemo uticati na proces usvajanja znanja. Iako nijedan od autora ne odbacuje sumativni tip evaluacije, ističe se potreba da „u pristupu orijentisanom na učenika [...], učenici budu uključeni u sve procese učenja, uključujući i proces evaluacije" (Little 2005: 322). A kao jedan od ključnih načina postizanja ovakvog cilja navodi se samoevalucija kao proces koji odslikava paradigmatsku promenu od bihejviorističkog modela učenja kao prenosa znanja do konstruktivističkog modela transformacije znanja (Kohonen 1992: 81).

Neophodno je, ipak, dati približniju definiciju ovoga pojma kako ćemo ga posmatrati u ovom radu, jer različiti autori pod ovim terminom podrazumevaju različite stvari, najčešće u zavisnosti od svrhe u koju se obavlja. Tako neki od autora prave distinkciju između učinkovito-orijentisane i razvojno-orijentisane samoevaluacije gde prvi tip predstavlja samoprocenu ukupnog znanja jezika u određenom trenutku, dok drugi označava zadatke kojima učenik ocenjuje svoj postepeni napredak tokom dužeg perioda učenja (Saito 2003: 12). Drugi pak razlikuju samoevaluaciju kao sumativni tip ocenjivanja čiji rezultati ulaze u krajnju ocenu učenika i samoprocenu kao formativni tip koji nema direktnog uticaja na finalnu ocenu (Andrade/Valcheva 2008: 13). U ovom tekstu, mi ćemo naizmenično koristiti termine samoevaluacija i samoprocena za razvojno-orijentisano formativno ocenjivanje sopstvenih sposobnosti od strane učenika koje nema neposredan uticaj na krajnju ocenu. Posmatrana u ovom kontekstu, samoevaluacija ima daleko šire značenje od toga da učenici sami ocenjuju sopstveni 
rad; ona predstavlja proces u kom učenici aktivno razmišljaju o kvalitetu svog rada ili pokazanog znanja, procenjuju u kojoj meri on ispunjava željene ili zadate kriterijume i modifikuju svoj rad i angažman na osnovu date procene (Andrade 2010: 92). Na ovaj način podstiče se učenje kako se uči - jedna od ključnih kompetencija za razvoj doživotnog učenja - te se sve veći akcenat stavlja na njeno integrisanje u formalne školske sisteme.

\section{ZNAČAJ UDŽBENIKA ZA RAZVOJ SPOSOBNOSTI SAMOEVALUACIJE}

Udžbenik predstavlja jednu od osnovnih komponenti procesa obrazovanja, a njegov značaj ogleda se u tome da je za gotovo svaki od predmeta u okviru osnovnog $i$ srednjeg školovanja nastavnicima na raspolaganju više zvanično odobrenih udžbenika. U ovom smislu, udžbenik ne čine samo pojedinačne knjige, već i sva prateća učila koja čine udžbenički komplet: knjige, radne sveske, priručnici, zbirke zadataka i audio-vizuelni materijal. Posebno didaktičko oblikovanje materijala u udžbeničkom kompletu ima za svrhu da pomogne učenicima pri aktivnom konstruisanju znanja (Ivić/Pešikan/Antić 2012: 24) i u školi i van nje, kako bi se uzele u obzir potrebe savremenog obrazovnog sistema i pomoglo u stvaranju nezavisnih učenika. Ovo se pre svega postiže preko zadataka koji podržavaju aktivno učešće učenika u nastavnom procesu, promovišu saradnju i kooperativno učenje i zahtevaju sposobnost refleksije, što indirektno - kroz pitanja i zahteve koji traže od učenika da zauzmu stav ili iskažu mišljenje - što direktno kroz zadatke namenjene samoevaluaciji. Ovi potonji najčešće su rasprostranjeni upravo u udžbenicima namenjenim nastavi stranog jezika. Kako je samoevaluacija kao osnov autonomnog učenja ušla u teoriju nastave i aktivnim angažovanjem Saveta Evrope pronašla svoje mesto u nastavi stranih jezika kroz razvoj alatki kao što je Evropski jezički portfolio, tako su i aktivnosti za samoevaluaciju u pojednostavljenom obliku našle put do udžbenika stranih jezika. Ovi zadaci najčešće se nalaze na kraju didaktičke celine - lekcije ili modula - i imaju za cilj da pomognu učeniku da proceni šta je od predstavljenog sadržaja usvojio, a na čemu još treba da poradi, kao i da li mu je za to neophodna pomoć nastavnika.

U zavisnosti od uzrasta učenika, aktivnosti za samoevaluaciju mogu se pojaviti u više različitih oblika. Na nižim nivoima, kod učenika koji još uvek nisu savladali latinično pismo, ovi zadaci obično su slikovnog tipa - gde sličice predstavljaju ključni vokabular u okviru određene lekcije ili modula - i zahtevaju od učenika da nacrtaju nasmešeno lice pored onih reči koje su u stanju samostalno da reprodukuju na stranom jeziku. Na nešto starijem uzrastu, kada učenici savladaju veštine čitanja i pisanja, slikovni zadaci često se kombinuju sa pisanim funkcionalnim kriterijumima, kao što su na primer izjave tipa "ja umem" ili „ja mogu". Zbog njihove jednostavnosti i prisustva vizuelne komponente nije redak slučaj da su ove izjave predstavljene na jeziku koji se usvaja, što ujedno uvodi učenike u osnove čitanja i pisanja stranog jezika.

Zadaci za starije učenike često odslikavaju strukturu gradiranih deskriptora postignuća Evropskog jezičkog portfolija, i sastoje se od pozitivno formulisanih tvrdnji (can do statements) koje predstavljaju znanja i funkcije koje učenik ume da demonstrira ili primeni (na primer: Umem da govorim o prošlim događajima/napišem kratku priču/ 
opišem svoju sobu). U nekim udžbenicima, ove tvrdnje praćene su primerima koje učenici treba da popune pre nego što označe da li mogu ili ne mogu da izvedu navedene radnje, dok su u drugima dekontekstualizovane i podrazumevaju metaanalitičku svest kod korisnika. U nekim slučajevima uz svako pitanje postoji i gradirana skala sposobnosti, najčešće na tri nivoa: mogu to da uradim lako - uz par problema - teško. Osim što se na ovaj način izbegava drastičnost dihotomije znam-ne znam, koja može da demotiviše učenike, gradirana skala ima i svrhu osvešćivanja učenika o realnoj prirodi jezičkog znanja gde je moguće dostići različite nivoe kompetencije u različitim veštinama.

Osim što predstavlja svojevrsni izvor i model zadataka za samoevaluaciju, udžbenik igra značajnu ulogu i kao sredstvo obuke nastavnika. Istraživanje sprovedeno između marta i avgusta 2015. godine na 62 nastavnika engleskog jezika iz osnovnih škola širom Srbije pokazalao je da je za čak $70 \%$ ispitanika priručnik za nastavnike iz udžbeničkog kompleta bio primarno sredstvo instrukcije u organizaciji aktivnosti samoevaluacije (Gligorić 2016). Iz dobijenih rezultata možemo zaključiti da je na nivou osnovne škole uticaj udžbenika daleko veći od uticaja koji imaju drugi vidovi obuke, kao što su seminari ili istraživački radovi, barem kada je usvajanje engleskog kao stranog jezika u pitanju. Pri organizaciji samoevaluacije, nastavnici koriste udžbenik i kao izvor materijala i kao tutorijal za sprovođenje dotičnih aktivnosti u svakodnevnoj nastavnoj praksi. Udžbenik je, dakle, nezamenljivi element razvoja sposobnosti samoevaluacije i samoregulativne sposobnosti kod učenika, te dizajniranju ovih aktivnosti treba pristupiti sa izuzetnom pažnjom.

\section{GRADIRANJE I KOOPERATIVNOST KAO OSNOVNE KARAKTERISTIKE ZADATAKA ZA SAMOEVALUACIJU}

Videli smo da je udžbenik značajan faktor razvoja sposobnosti za samoevaluaciju kod učenika, te da didaktičko oblikovanje zadataka za samoevaluaciju (uključujući i prateće instrukcije u priručniku za nastavnike) treba da prati preporučenu praksu kako bi se poboljšao razvoj samoregulisanog učenja i autonomije učenika, ali i olakšao posao nedovoljno obučenim nastavnicima. U okviru školskog sistema, autonomija u učenju ne posmatra se više kao samostalno preuzimanje odgovornosti za sopstveno učenje bez ikakve podrške ili obuke, već kao „preuzimanje sve veće kontrole učenika nad sopstvenim učenjem" (Benson 2011: 16) u socijalnom okruženju učionice, na način koji Bruner (1986) naziva podupiranjem ili modelom građevinske skele (scaffolding) u kome nastavnik u ulozi medijatora sistematski pomaže učeniku, pružajući pomoć kad i gde je neophodna, da bi u pravom trenutku "skinuo skelu" i tako mu omogućio da samostalno upravlja procesom učenja. Ovakvo tumačenje implicira da se sposobnost samoprocene neophodne za razvoj autonomije ne može postići odjednom ili u izolaciji, već podrazumeva postepenost obuke kroz međusobnu saradnju, kako na relaciji nastavnik-učenik, tako i u interakciji između vršnjaka.

Značaj uloge vršnjaka u procesu usvajanja znanja ističe se u teoriji socijalnog učenja Alberta Bandure (Bandura 1963, 1977), koja „naglašava ulogu socijalne opservacije u pružanju informacija o zahtevima zadatka i efikasnim strategijama za postizanje uspeha" (Butler 1989: 1350). Bandura navodi kako vršnjaci imaju formativni uticaj na 
razvoj samo-efikasnosti kao uverenja osobe o vlastitim sposobnostima izvršenja nekog zadatka (Bandura 1997: 173). Prema ovoj teoriji, učeniku kontekstu učionicenijeizolovana jedinka koja dela nezavisno od ostalih, već socijalno biće koje svoju kritičku svest, a samim tim i sposobnost samoprocene, najlakše razvija u interakciji sa drugima. Upravo iz ovog razloga veliki broj autora (McKay 2006; Cameron 2001; Ross 2006; Perry/Hutchinson/ Thauberger 2008) zalaže se za vršnjačku evaluaciju - gde učenici pod vođstvom nastavnika primenjuju postavljene kriterijume da bi ocenili radove jedni drugima - kao prelaznu fazu u razvoju sposobnosti samoevaluacije. Ovakav pristup predstavlja izvesnu praksu učenicima koji se postepeno vežbaju da samostalno procenjuju svoje znanje, čime se postiže i bolje razumevanje standarda i kriterijuma ocenjivanja.

Vidimo, dakle, da su ključni parametri pravilno organizovanih aktivnosti samoevaluacije upravo gradiranost i kooperativnost, te da se ova dva principa moraju uzeti u obzir pri dizajniranju zadataka, ukoliko nam je cilj razvoj samoregulacije i autonomije u učenju. Prema navodima Snežane Mirkov: „Vežbanje u primeni samoregulativnih strategija, prvo vođeno a zatim samostalno, [...] utiče i na usavršavanje učenja" (Mirkov 2007: 325), dok Peri, Hačinson i Tauberger tvrde da „deca razvijaju akademski efikasne oblike [samoregulisanog učenja] kada [...] su u prilici da [...] procenjuju sopstveno učenje; i rade u saradnji sa i tražeći povratnu informaciju od svojih vršnjaka" (Perry/Hutchinson/Thauberger 2008: 98).

Postojeće aktivnosti za samoevaluaciju u odobrenim udžbenicima engleskog kao stranog jezika dizajnirani su sa fokusom na pojedinca koji samostalno procenjuje svoje jezičko znanje od samog početka kursa, dok se postepena obuka kroz eventualnu saradnju sa vršnjacima ostavlja često nedovoljno obučenim nastavnicima. Jedan od mogućih načina na koji bi aktivnosti za samoevaluaciju u udžbenicima engleskog kao stranog jezika zadovoljavale kriterijume gradiranosti i kooperativnosti bio bi da uključuju „pripremne faze" timske evaluacije (collaborative assessment), praćene vršnjačkom evaluacijom (peer assessment), pre uvođenja samostalne samoprocene (self assessment). Kooperativni aspekat ogledao bi se $u$ formi zadatka koji bi bio direktno vezan za pređenu nastavnu jedinicu, visoko kontekstualizovan i zahtevao od učenika da u parovima ili timovima izvrše određene komunikativne radnje, nakon čega bi sledila ocena uspešnosti izvedbe kooperativnog zadatka u odnosu na postavljene kriterijume (upotreba engleskog/maternjeg jezika, broj načinjenih grešaka, traženje pomoći od nastavnika, razumljivost odgovora, procena sposobnosti primene testiranog gradiva u stvarnom životu van učionice). U zavisnosti od broja nastavnih jedinica, ovaj deo zadatka bi u prvom delu udžbenika zahtevao od učenika u okviru jednog para da zajednički ocene uspeh tima, u drugom tražio od pojedinačnih učenika da procene uspeh svog kolege pri zajedničkom izvršavanju zadatka, dok bi u poslednjoj fazi svaki učenik bio upitan da izvrši samoprocenu sopstvenog učinka nakon obavljenog timskog rada. Gradirana priroda ovih zadataka podržava ideju postepene obuke učenika u samoproceni sopstvenog jezičkog znanja preko timske i vršnjačke evaluacije, dok njihova kooperativna priroda podržava ideje Vigotskog i Brunera 0 konstruktivističkom učenju i aktivnoj izgradnji znanja kroz međusobnu saradnju. U isto vreme, ovakav način didaktičkog oblikovanja aktivnosti samoevaluacije pružio bi neophodnu podršku nastavnicima kojima je udžbenik primarni vid informisanja na polju učeničke autonomije. 


\section{ZAKLJUČAK}

Istraživanja pokazuju da uključivanje učenika u proces evaluacije ima pozitivne efekte na njihov progres, kao i na celokupan proces usvajanja znanja. Ono im pomaže da preuzmu veću odgovornost za sopstveno učenje, kao i da sami postavljaju ciljeve i biraju strategije kojima će do njih stići. U kontekstu usvajanja stranog jezika u školskim uslovima, udžbenik je nezamenljiva komponenta razvoja sposobnosti samoevaluacije jer predstavlja najdostupniji vid gotovog nastavnog materijala, ali nekada i jedinu metodološku podršku nastavnicima koji ove aktivnosti organizuju. Kako bi obuka učenika samoevaluaciji bila uspešna, neophodno je da bude postepena i da obuhvata socijalnu komponentu. Na ovaj način, ona će imati direktan uticaj na postignuće, ali i indirektan uticaj na rezultate učenja kroz povećanu samostalnost i razvoj autorefleksivne svesti koja će imati primenu i van sveta učionice ili konteksta učenja jezika.

\section{LITERATURA:}

Andrade, H. 2010. Students as the Definitive Source of Formative Assessment: Academic Self-Assessment and the Self-Regulation of Learning. In H. Andrade \& G. Cizek, (eds.). Handbook of formative assessment. New York: Routledge, 90-105.

Andrade, H. i A. Valtcheva. 2008. Promoting Learning and Achievement Through SelfAssessment. Theory Into Practice, vol. 48/1, 12-19.

Bandura, A. 1997. Self-efficacy: the exercise of control. New York: W.H.Freeman.

Bandura, A. 1977. Social Learning Theory. Englewood Cliffs, NJ: Prentice-Hall.

Bandura, A. i R. H. Walters. 1963. Social Learning and Personality Development. New York: Holt, Rinehart and Winston.

Benson, P.2001. Teaching and Researching Autonomyin Language Learning. Pearson Longman.

Boud, D. 2000. Sustainable assessment: rethinking assessment for the learning society. Studies in Continuing Education, 22, 2, 151-167.

Butler, R. 1989. Mastery versus Ability Appraisal: A Developmental Study of Children's Observations of Peers' work. Child Development, vol.60, no.6, 1350-1361.

Bruner, J. 1986. Actual Minds, Possible Worlds. Cambridge, Massachusetts: Harvard University Press.

Cameron, L. 2001. Teaching Languages to Young Learners. Cambridge: Cambridge University Press.

Cooker, L. 2015. Learner autonomy. In Carol J. Everhard and Linda Murphy,(eds.). Assessment and Autonomy in Language Learning. New York: Palgrave Macmillan, 89-113.

Gligorić, S. 2016. The Influence of Language Policy and Socio-Political Context on Interpreting the Meaning of Student Autonomy - The Teachers' Perspective. U Biljana Mišić-Ilić i Vesna Lopičić (ur.): Jezik, Književnost, Značenje, Zbornik radova. Niš: Filozofski fakultet, 701-714.

Hamp-Lyons, L. 2007. The Impact of testing practices on teaching: Ideologies and alternatives. In J. Cummins and C. Davidson, (eds.). The International Handbook of English Language Teaching, Vol.1. Norwell, MA: Springer, 487-504.

Holec, H. 1981. Autonomy in Foreign Language Learning. Oxford: Pergamon. 
Ivić, I, A. Pešikan i S. Antić. 2012. Vodič za dobar udžbenik - opšti standardi kvaliteta udžbenika, Beograd: Klett.

Klenowski, V. 1995. Student Self-evaluation Processes in Student-centred Teaching and Learning Contexts of Australia and England. Assessment in Education, vol 2/2, 145-163.

Kohonen, V. 1992. Foreign Language Learning as Learner Education: Facilitating Self-Direction in Language Learning, Transparency and coherence in language learning in Europe - Objectives, evaluation, certification. Report on the Rüschlikon Symposium. Strasbourg: Council of Europe, 71-87.

Little, D. 2005. The Common European Framework and the European Language Portfolio: Involving Learners and Their Judgements in the Assessment Process. Language Testing, vol 22/3, 321-336.

McKay, P. 2006. Assessing Young Language Learners. Cambridge: Cambridge Unversity Press.

Mirkov, S. 2007. Samoregulacija u učenju: Primena strategija i uloga orijentacija na ciljeve. Zbornik Instituta za pedagoška istraživanja, br. 2, 309-328.

Perry, N. E, L. Hutchinson i C. Thauberger. 2008. Talking about teaching self-regulated learning: scaffolding student teachers' development and use of practices that promote self-regulated learning. International Journal of Educational Research 47, 97-108.

Rowntree, D. 1977. Assessing Students.London: Harper \& Row.

Saito, Y. 2003. The Use of Self-assessment in Second Language Assesment. Teachers College, Columbia University Working Papers in TESOL \& Applied Linguistics, vol. 3/1. [Internet]. Dostupno na: www.tc.columbia.edu/academic/tesol/WJFiles/pdf/Saito_ Forum.pdf [12. Feb.2011]

Vrhovac,Y.ij. Mihaljević Djigunović. 2010.Stavovi kao indikatoriučenikovesamostalnosti u učenju stranoga jezika - prikaz rada s Europskim jezičnim portfolijom. U J. Vučo; B. Milatović (ur.), Autonomija učenika i nastavnika u nastavi jezika i književnosti, Zbornik radova. Nikšić: Filozofski fakultet, 236-249.

\section{SUMMARY}

\section{DESIGNING SELF-ASSESSMENT ACTIVITIES IN EFL COURSEBOOKS}

Student autonomy is a term which is gaining popularity in language learning literature, and represents the student's ability to take responsibility for his or her own learning. The purpose of this paper is to introduce self-assessment as a key component in obtaining student autonomy in institutional EFL learning, and to underline the importance of the coursebook in developing self-assessment skills. Particular attention is given to the key principles of designing self-assessment task for EFL coursebooks and the influence they have over the teaching practice.

KEYWORDS: self-assessment, self-regulated learning, the theory of social learning.

(Originalni naučni rad primljen 28.1.2017;

ispravljen 1.3.2017;

prihvaćen 20.10.2017) 